\title{
Implantable Neural Probes for Brain-Machine Interfaces - Current Developments and Future Prospects
}

\author{
Jong-ryul Choi ${ }^{1}$, Seong-Min Kim ${ }^{2,3}$, Rae-Hyung Ryu ${ }^{4}$, \\ Sung-Phil Kim ${ }^{5}$ and Jeong-woo Sohn ${ }^{2,3 *}$ \\ ${ }^{1}$ Medical Device Development Center, Daegu-Gyeongbuk Medical Innovation Foundation (DGMIF), Daegu 41061, \\ ${ }^{2}$ Department of Medical Science, College of Medicine, Catholic Kwandong University, Gangneung 25601, \\ ${ }^{3}$ Biomedical Research Institute, Catholic Kwandong University International St. Mary's Hospital, Incheon 21711, \\ ${ }^{4}$ Laboratory Animal Center, Daegu-Gyeongbuk Medical Innovation Foundation (DGMIF), Daegu 41061, \\ ${ }^{5}$ Department of Human Factors Engineering, Ulsan National Institute of Science and Technology (UNIST), Ulsan 44919, Korea
}

A brain-machine interface (BMI) allows for direct communication between the brain and machines. Neural probes for recording neural signals are among the essential components of a BMI system. In this report, we review research regarding implantable neural probes and their applications to BMIs. We first discuss conventional neural probes such as the tetrode, Utah array, Michigan probe, and electroencephalography $(\mathrm{ECoG})$, following which we cover advancements in next-generation neural probes. These next-generation probes are associated with improvements in electrical properties, mechanical durability, biocompatibility, and offer a high degree of freedom in practical settings. Specifically, we focus on three key topics: (1) novel implantable neural probes that decrease the level of invasiveness without sacrificing performance, (2) multi-modal neural probes that measure both electrical and optical signals, (3) and neural probes developed using advanced materials. Because safety and precision are critical for practical applications of BMI systems, future studies should aim to enhance these properties when developing next-generation neural probes.

Key words: Implantable neural probes, Brain-machine interface, Multi-channel electrodes, Neural probes with advanced materials

\section{INTRODUCTION}

Brain-machine interfaces (BMIs) enable direct communication between the brain and machines $[1,2]$. Due to advancements in information and communication technology, BMIs have gained

Received October 5, 2018, Revised November 15, 2018,

Accepted November 15,2018

* To whom correspondence should be addressed. TEL: 82-32-280-6523, FAX: 82-32-280-6510 e-mail: jsohn@ish.ac.kr attention for their promising applications in medical, industrial, and household settings [3-6].

In a unidirectional BMI, the system consists of three components: devices used to record neural signals, components used to analyze the signals, and devices used to provide commands to operate the machine, as illustrated in Fig. 1. In a bidirectional BMI, additional components are required to provide feedback from the machine to the brain $[7,8]$. While both invasive and non-invasive methods have been developed for the acquisition of neural signals, the present review focuses on implantable neural probes. Thus, hereafter, we will use the terms "neural probes" and "invasive meth- 


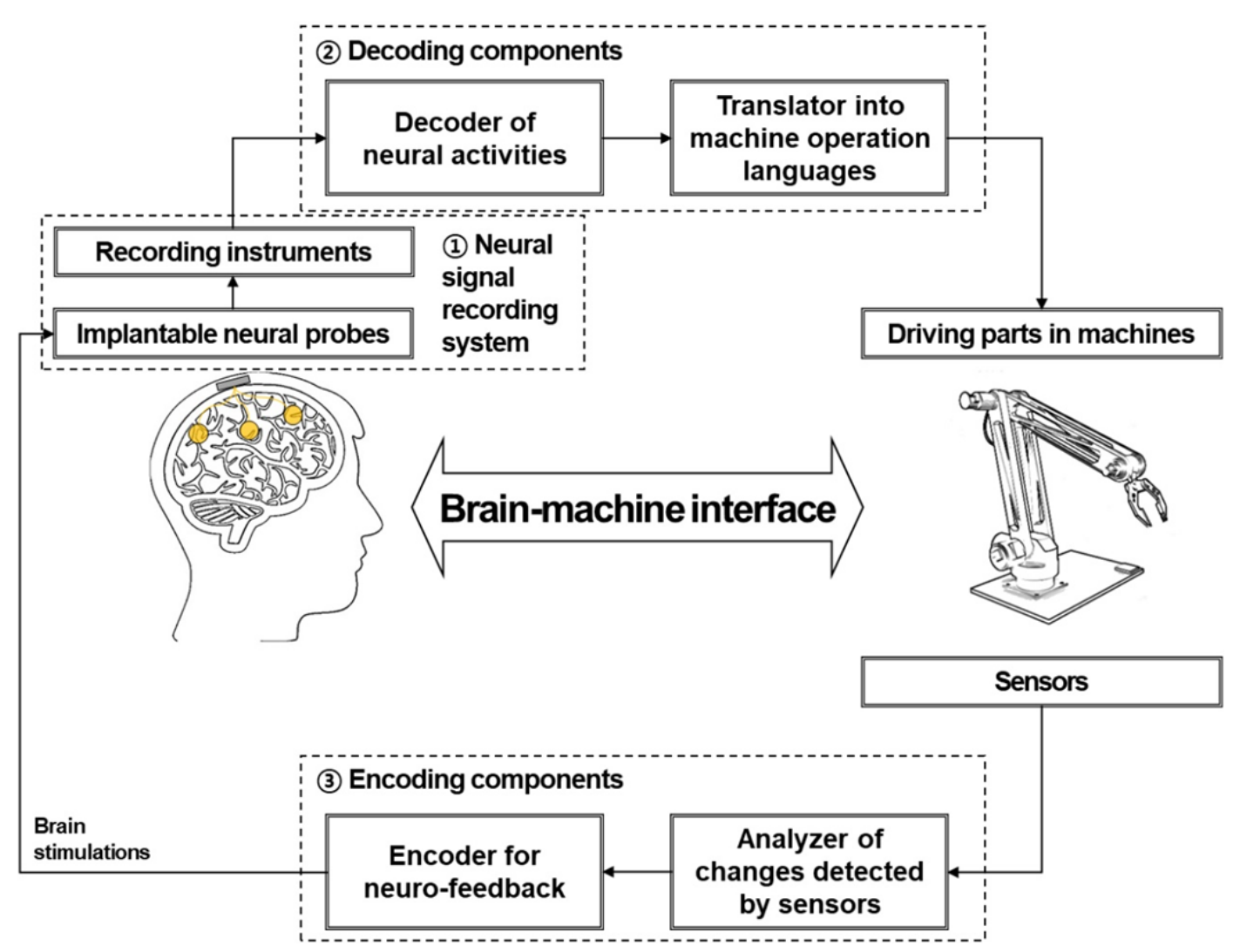

Fig. 1. A schematic of a bidirectional brain-machine interface. As the figure illustrated, the system of brain-machine interface consists of three components. First one is the system that acquires neural signal, for example, neural recording systems with a neural probe. Second one is decoding component to translate neural activities into machine operational languages. Third one is encoding component that analyze feedback data from sensors and stimulate the specific regions in the brain. A fundamental concept in the bidirectional interface is referred to [8] with a permission of Frontiers Media S.A. under the terms of the Creative Commons Attribution License (CC BY).

ods" interchangeably.

Electroencephalography (EEG) is widely utilized in non-invasive BMI systems due to its high temporal resolution, which makes it useful for mapping associations between EEG signals and cognitive function [9-11]. For example, NeuroSky, Inc. (San Jose, CA, USA) introduced an EEG-based brain-medicine interfacing headset for use in healthcare settings. In addition, Emotiv, Inc. (San Francisco, CA, United Sates) provides a 14-channel system for measuring EEG and other bio-signals for use in brain-computer interfacing games and neurofeedback treatment. Functional nearinfrared spectroscopy (fNIRS) and magnetoencephalography (MEG) have also been used to develop non-invasive BMI systems [12-15]. However, non-invasive neural methods are limited in that neural signals from non-invasive probes are typically insufficient for complicated tasks that require a high degree of freedom, such as robot control [16-19]. For this reason, implantable neural probes are preferred for BMI systems that demand accurate controls and adjustments (e.g., neuroprosthetic devices).

Implantable neural probes are defined as devices implanted into the brain or other nervous tissues. Communication between neurons in the brain occurs via electrical and chemical signals. In most cases, electrical signals are the main source of information in BMI systems. In particular, single-unit activity (i.e., spikes) is regarded as most appropriate for extracting meaningful information, such as movement-related activity [20]. While non-invasive methods record neural activity through different media such as the dura matter, cerebral spinal fluid (CSF), and skull, implanted neural probes can record extracellular activity or local field potentials closer to neurons. To maximize the signal-to-noise ratio, the conductive material is often exposed at the end of the electrode, the shank of which is insulated with non-conductive material. Typically, single-wire electrodes [21] and glass micropipette electrodes are used in electrophysiological studies [22, 23]. Recent advancements have enabled the development of implantable neural probes with the technical characteristics necessary for practical BMI applications, which include high spatiotemporal resolution and high signal-to-noise ratio. Biocompatibility, biochemical stability, and miniaturization are also important, as neural probes must be 
inserted into the brain. Indeed, implantable multi-array neural probes with these characteristics have been developed and applied for research, diagnosis, and treatment purposes. Representative neural probes in this category include the tetrode, Utah array, and Michigan probe.

In the present report, we review the features of these three implantable neural probes and their applications in BMI systems. Furthermore, we describe several novel technical approaches for improving the measurement of neural signals in BMI systems: (1) decreasing the invasiveness of implantable neural probes while maintaining performance, (2) using multi-modal probes to measure both electrical and optical signals from neurons, and (3) using flexible neural probes to enhance signal quality and biocompatibility. We further discuss (4) novel fabrication techniques and materials that can be utilized to improve neural probes. By exploring recent developments in implantable neural probe technology, we offer insight into the performance required to create practical, efficient, and accurate BMI systems.

\section{APPLICATION OF IMPLANTABLE NEURAL PROBES IN BMIs}

BMIs have been successfully applied in the field of neuroprosthetics, enabling patients with paralysis to control robot arms using their thoughts. The underlying neural principle of this phenomenon involves population vectors, in which each neuron "votes" for the intended movement [20]. Increasing the number of neuronal signals increases the likelihood of movement in the population vector. Thus, probes including a high number of channels are suitable for BMIs. In this section, we discuss three popular implantable neural probes with high numbers of channels.

\section{TETRODE}

The tetrode is widely utilized to record extracellular electrical potentials in neural systems. As the prefix (tetr-) indicates, the tetrode consists of four electrodes at which neuronal signals are detected from slightly different spatial points originating from the same source. Such electrodes are typically constructed from a platinumtungsten alloy and insulated with quartz coating. The metal end of the electrode is exposed to acquire electrical signals. The diameter of each electrode at the metal end is usually less than $30 \mu \mathrm{m}$, and may be up to $100 \mu \mathrm{m}$ at the coated end. The coating functions to minimize the interference of electrophysiological signals across electrodes. As illustrated in Fig. 2A, a single tetrode can measure the extracellular potentials of approximately 1,100 neurons within a $140-\mu \mathrm{m}$ radius in the rat cortex [24-26]. One main advantage of this method over single-channel electrodes is that users can classify the extracellular potentials of adjacent neurons using a clustering approach [27-29]. The extracellular potentials of each neuron are detected by the four electrodes in the tetrode with different temporal points and waveforms because due to the difference in spatial distance between each electrode and the neuron. Spikes from multiple neurons can thus be separated in the post-processing stage. However, the tetrode cannot provide direct measurements of spatially multi-dimensional extracellular potential distributions unless multiple tetrodes are precisely implanted and arranged at regular intervals. Recently, several research groups have developed multi-tetrode arrays to compensate for these shortcomings [30,
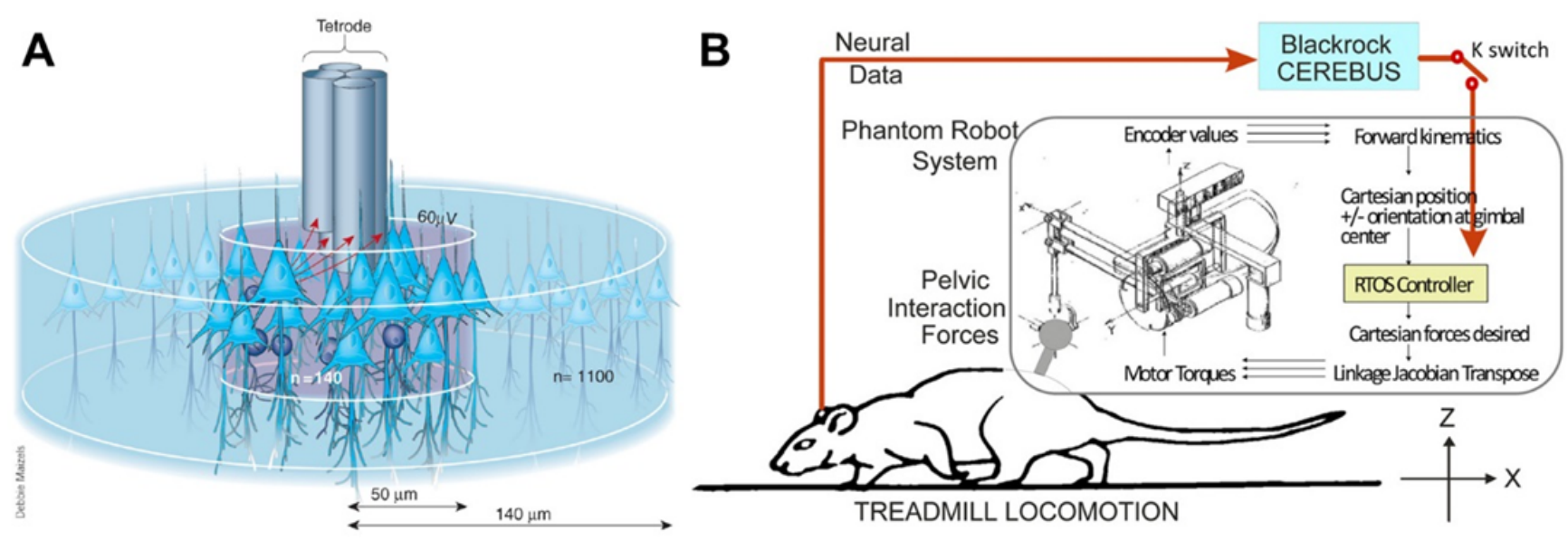

Fig. 2. (A) A schematic to represent detectable areas of neural activities by a tetrode. By improved clustering and spike sorting methods, the tetrode can detect neural activities in areas of neural assembles with $280 \mu \mathrm{m}$ diameters. The reprint of this figure in [26] was permitted by Nature Publishing Group (Springer Nature). (B) A schematic of an experimental setup to study the control of a robot by neural signals recorded by multiple tetrodes, which were implanted in the cortex of the rat. This figure published in [34] is reprinted with a permission of Society for Neuroscience. 
$31]$.

The tetrode has been used as an implantable neural probe in BMI platforms, especially in small animals. Giszter et al. described a neurorobotic platform, which consisted of a tetrode-based neural recording module and a three-dimensional (3D) robotic module, for use with spinal or cortical prosthetics in small animals (i.e., frogs and rats) [32]. Song et al. developed a novel BMI system to identify movement-related information in the rat cortex during treadmill walking [33]. Using decoded neural activity acquired from six implanted tetrodes, specific regions related to proximal limb and trunk movements were identified in the rat motor cortex. In a follow-up study, Song and Giszter introduced a pelvis- attached robot that can be controlled by cortical neural signals using a multi-tetrode array implanted in the rat brain (Fig. 2B) [34]. Bender et al. investigated that activity of central complex neurons in the insect brain during walking using a tetrode-based system [35]. The authors reported a close association between movements and sensory responses, providing insight into the feasibility of such methods for use in larger animals with more developed brains. Additional groups have also reported advancements in post-processing techniques that enable sorting of spikes in practical BMI systems. For example, Oweiss introduced a novel spatiotemporal signal processing method to improve data compression and reduce latency in multi-tetrode BMI systems [36]. Kubo et
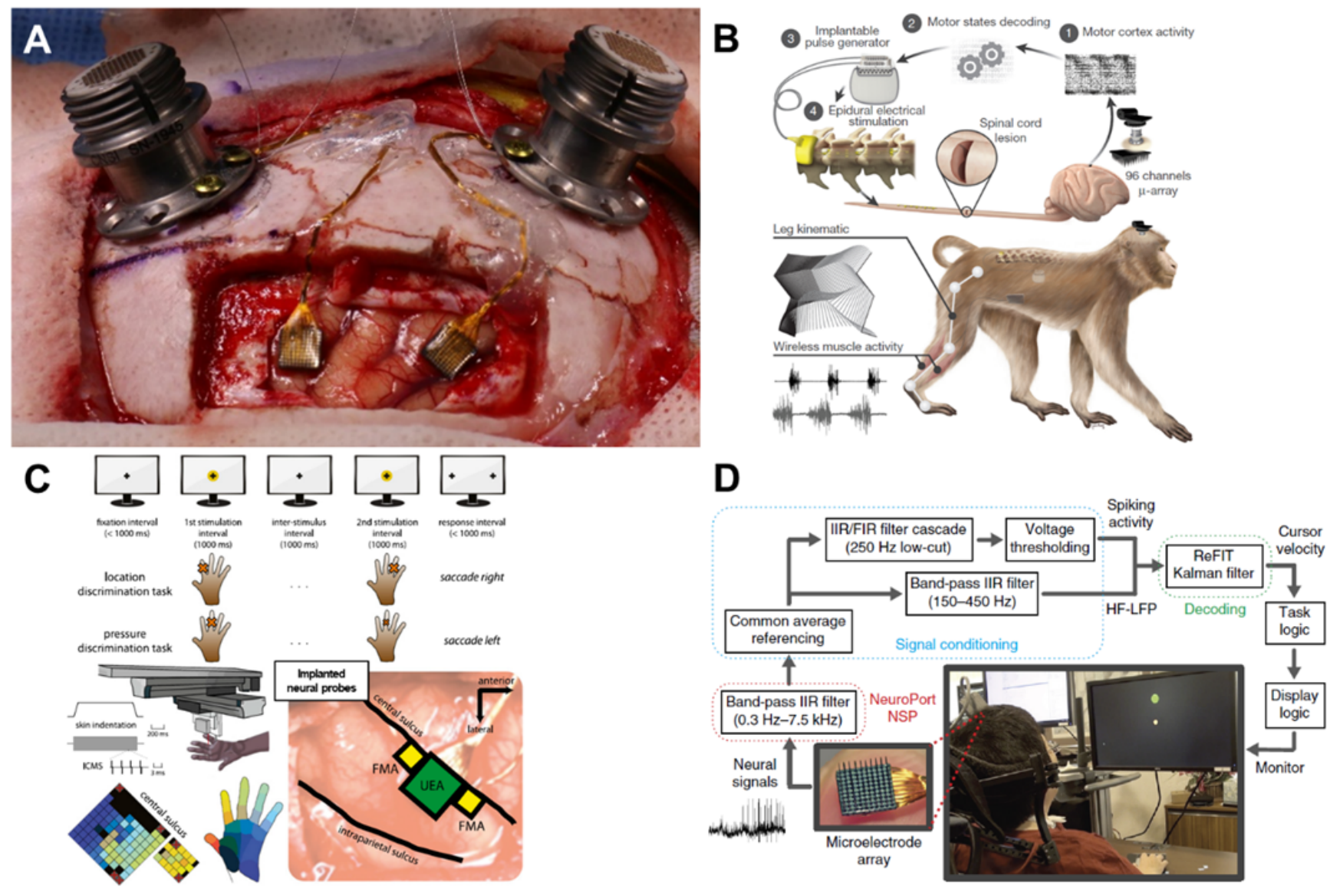

Fig. 3. (A) A figure of implanted two 96-channel Utah arrays on a motor and posterior cortex of a non-human primate to record neural signals for an investigation of a brain-machine interfacing platform under approve of Institutional Animal Care and Use Committee at Daegu-Gyeongbuk Medical Innovation Foundation, Korea. (B) A schematic of a brain-spine interface to produce the signal of the spinal cord for walking based on neural activities of the motor cortex. To be specific, neural activities of the motor cortex were recorded by a 96-channel Utah array and decoded information from the acquired neural activities was transmitted to an electrical pulse generator inserted in the spine. The pulse generator produced electrical stimulations for walking of a spine-injured non-human primate. The re-use of this figure published in [41] was permitted by Nature Publishing Group (Springer Nature). (C) Experimental procedures, a technological setup, and a map of implanted Utah and floating electrode arrays for generating contacting senses in an artificial hand with targeted neuro-stimulations in the somatosensory cortex. This figure in [42] is re-used with a permission of National Academy of Sciences. (D) A schematic of a paralyzed patient assistant platform based on on-site available neural cursor adjustments from neural signals, which were measured by implanted Utah array. A right figure illustrates radial-8 cursor trajectories of three participants (S3, T6, and T7). The re-use of this figure published in [47] was approved by Nature Publishing Group (Springer Nature). 
al. further investigated the 3D distributions of neurons based on multi-site neural activity using the tetrode [37].

\section{UTAH ARRAY}

Advancements in semiconductor fabrication processes during the late $20^{\text {th }}$ century have led to the development of multichannel arrays that perform better than single-channel electrodes in multiple respects. The Utah array is a commercially available intracortical electrode array consisting of up to 100 silicon needleshaped electrodes, which are produced via microscale fabrication techniques such as thermomigration, a combination of mechanical and chemical micromachining, metal deposition, and encapsulation with a polymer made of imide monomers [38]. Due to the large number of electrodes, the Utah array has been mostly used in large animals, especially non-human primates (Fig. 3A). Velliste et al. investigated the ability of a BMI system to provide neuroprosthetic arm control via cortical motor activity in rhesus monkeys (Macaca mulatta) using Utah arrays [39]. In this study, the BMI system produced natural levels of multi-dimensional arm and hand movements. In addition, the same research group reported meaningful associations between visuomotor adaptation and neural activity in the primary motor cortex measured via the Utah arrays [40]. Capogrosso et al. developed a BMI platform to electrically stimulate the spinal cord according to decoded neural signals from the Utah array in the motor cortex of monkeys [41]. As described in Fig. 3B, the brain-spine interface enabled monkeys with spinal cord injuries to walk again based on commands from the motor cortex. Utah arrays have not only been used for recording, but also for stimulation purposes. For example, Tabot et al. induced tactile sensations in the hand via targeted neural stimulation with Utah arrays implanted in the somatosensory cortex, as illustrated in Fig. 3C [42, 43]. This type of sensory feedback may aid in increasing the accuracy of various BMI devices and neuro-rehabilitation instruments. In addition, Suner et al. verified the reliability of chronic implementations of the Utah array in the brains of non-human primates [44].

The Utah array and its recording systems have been approved for clinical applications by the United States Food and Drug Administration (FDA). Several clinical trials of Utah array-based BMI systems involving human patients have been conducted. Simeral et al. reported that one patient with tetraplegia could control a computer cursor (including point-and-click functions) based on neural signals from the motor cortex [45]. Pandarinath et al. analyzed neural population dynamics during movement in two patients with amyotrophic lateral sclerosis (ALS) as they attempted to use their finger to move a computer cursor [46]. One year after implantation, the system still produced adequate signals for neural cursor control (Fig. 3D) [47] or virtual typing [48]. A more challenging task was performed by a human subject with Utah array implantation. Wodlinger et al. developed a BMI system for the control of an anthropomorphic robot arm and hand with 10 degrees of freedom [49]. Some studies have also indicated that BMI systems can bypass the spinal cord circuit to recover hand function in select patients. Bouton et al. introduced a platform for controlling a neuromuscular electrical stimulation sleeve using neural signals from an implanted Utah array, enabling the patient to perform accurate and continuous movements (e.g., grasp-pourand-stir tasks) [50]. Ajiboye et al. developed an interfacing platform between intracortical neural signals recorded by two Utah arrays and functional electrical stimulation of peripheral muscles to restore arm and hand movements in patients with paralysis [51]. As experiments of tactile feedbacks has been successful in nonhuman primate, this type of research has begun to be applied to human subject. As tactile feedback experiments using Utah arrays have been successful in non-human primates, researchers have begun to apply such systems in human patients. For example, Flesher et al. stimulated the somatosensory cortex using Utah arrays to recover tactile sensation in human patients [52].

\section{MICHIGAN PROBE}

The previous two neural probes enable users to acquire neural activity from different cortical areas. However, they are limited in their ability to target deep neural structures in the axial direction $[53,54]$. In the late 1970s, the first prototype of Michigan probe, a multi-channel depth electrode prototype, was developed based on electron-beam lithographic techniques [55], which was before production of Utah array. Several preclinical studies involving small animals have demonstrated the safety of long-term implantation for the Michigan probe, suggesting that such probes can be utilized in BMI systems [56-58]. Electrodes in the Michigan probe ( 2 to $15 \mathrm{~mm}$ ) are longer than those in the Utah array (0.5 to 1.5 $\mathrm{mm}$ for research). Thus, the Michigan probe may be more suitable when recording from deeper cortical structures.

Vetter et al. applied the Michigan probe to examine extracellular neural activity in the motor cortex of rats using a BMI system [56]. In a preclinical study on the control of emotions and memories, the Michigan probe was used to measure neural activity and provide electrical stimulation. Frost et al. investigated neural activity in the hindlimbs of rats with spinal cord injuries using a 16-channel Michigan probe and explored treatment methods based on neurostimulation [59]. Guggenmos et al. investigated the use of a neural interfacing system to recover neural function after brain injuries 

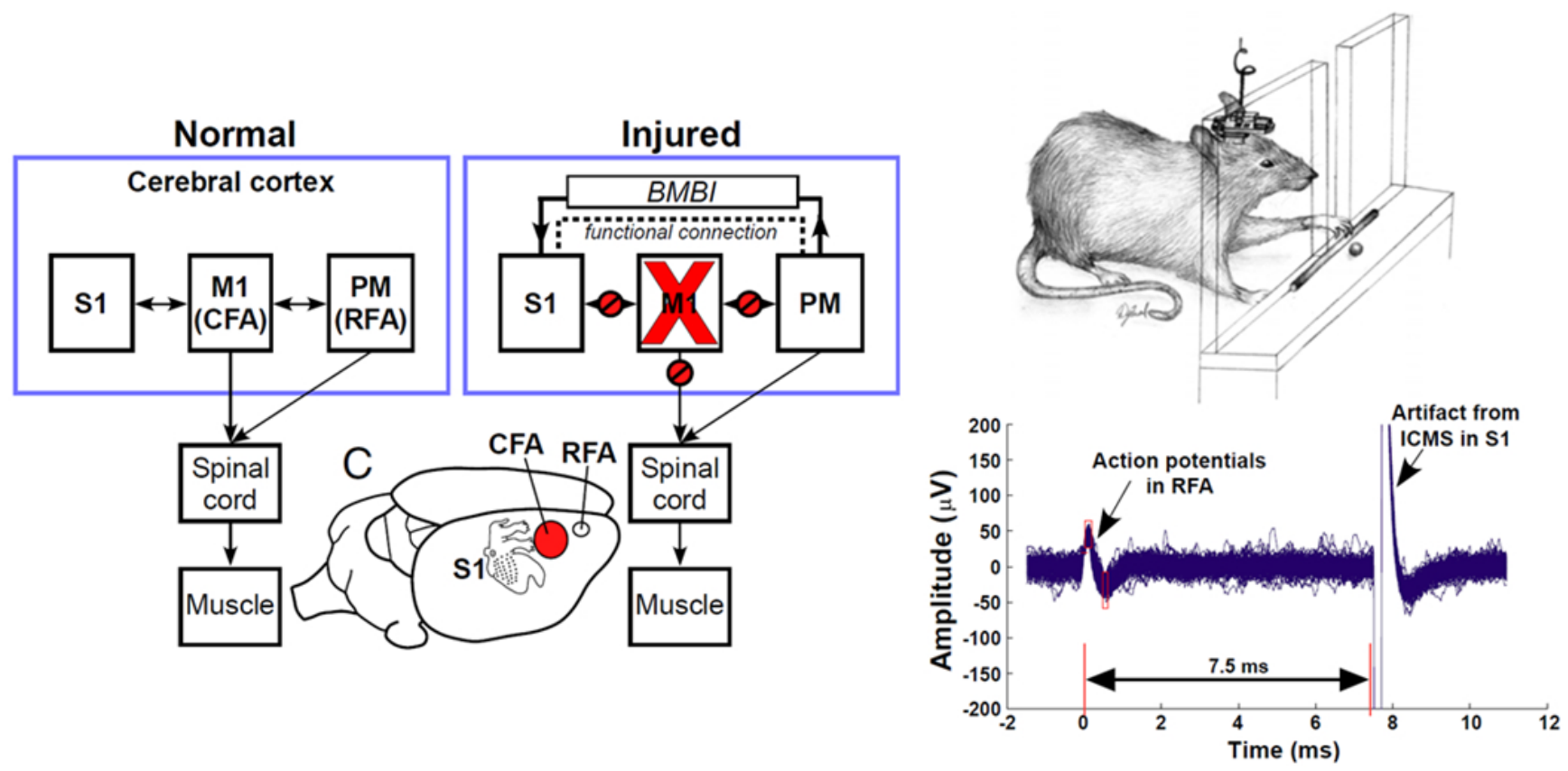

Fig. 4. A theoretical model of a neural interfacing system to recover neural functions after brain injuries by neuro-prosthetic treatments. A schematic of a preclinical test with an implanted Michigan probe was shown. The plot in the lower right corner shows transient neural signals and artifact due to an electrical stimulation from the premotor cortex. The reprint published in [60] was approved by National Academy of Sciences.

in small animals (i.e., rats) demonstrating that the missing brain functions can be restored using a brain-machine-brain interface as described in Fig. 4 [60]. Such findings suggest that neuroprosthetics can successfully applied in the treatment of various neural diseases. Michigan probes have also been validated in non-human primates [61], supporting the notion that such probes can be used to develop neuroprosthetic systems for use in humans.

\section{RECENT ADVANCES IN NEURAL PROBES FOR IMPROVE- MENTS OF BMI SYSTEMS}

In the previous session, we described the most widely used implantable neural probes in BMI applications. While the electrical characteristics, biological compatibility, and stability of these probes are sufficient, researchers have attempted to improve their impedance, flexibility, wireless communication, recording area, and accuracy to ultimately improve BMI systems. In this section, we present an overview of recent studies that have responded to these technical challenges for practical BMI applications.

NOVEL IMPLANTABLE NEURAL PROBES WITH DECREASING A DEGREE OF INVASIVENESS AND MAINTAINING PERFORMANCE

\section{High-performance ECoG electrode}

Electrocorticography (ECoG) is used to monitor signals from the cerebral cortex using electrodes placed on the surface of the brain (subdural) or dura matter (epidural). In contrast to implanted neural probes, which rely on single-unit activity, ECoG relies on local field potentials (LFPs). Although a craniotomy is still required to implement ECoG, no brain scarring occurs because the ECoG electrodes are not inserted into the brain tissue. ECoG provides more accurate neural signals than non-invasive approaches because due to direct (subdural) or close (epidural) contact with brain tissue. Since ECoG has clear advantages in terms of neural signal quality when compared with current non-invasive methods, it is widely used in the development of minimally invasive BMI systems [62-65]. Neural responses can be recorded from multiple sites in the human brain with high spatiotemporal resolution following tactile stimulation, supporting the use of ECoG in medical BMI applications [66]. For example, Wang et al. recorded activity in the human motor cortex during individual finger movement using micro-ECoG electrodes [67]. Subsequent studies demonstrated that a 32-channel ECoG electrode grid could be used to record LFPs in the sensorimotor cortex of a participant with tetraplegia [68]. Shin et al. introduced method for decoding muscle activation from neural activity based on ECoG signals in the motor cortex of non-human primates [69]. In this study, they investigated the potential for several advanced ECoG electrodes for use as neural probes in BMI systems.

Microfabrication techniques have been employed to develop 
high-resolution ECoG electrodes. Rubehn et al. developed a flexible, high-resolution (252 channels) ECoG electrode array to measure neural activity in the human brain by optimizing designs and implementing high-resolution MEMS fabrication techniques [70]. Henle et al. developed a microscale ECoG electrode array using a laser-based high-speed and high-resolution fabrication method [71]. Due to their biocompatibility, these types of electrode arrays are promising for use in various long-term, in vivo BMI applications. Toda et al. developed a mesh-type multi-channel ECoG electrode array with narrow spacing by simplifying fabrication steps, including oxygen plasma etching [72]. In a preliminary in vivo study, the authors measured neural signals in the rat visual cortex, reporting that ocular selectivity could be predicted with $90 \%$ accuracy by decoding the neural signals from their ECoG electrode array. Several research groups have proposed novel and optimized strategies for ECoG electrode arrangement. Slutzky et al. optimized the spacing of each ECoG electrode to reduce invasiveness in ECoG-based BMI systems without sacrificing performance using finite element modeling of the electrical and physical properties of each component (i.e., scalp, skull, etc.) in the brain [73]. Tolstosheeva et al. investigated the application of a flexible ECoG neural probe (Fig. $5 \mathrm{~A}$ ) consisting of electrodes with three different sizes efficiently distributed on a soft pad $[74,75]$.

Advancements in ECoG recording systems have occurred with regard to both detection and transmission. Indeed, several studies have suggested that wireless ECoG recording systems can be implemented in BMI systems. For instance, Charvet et al. developed a promising wireless 64-channel neural probe for the acquisition of neural activity as recorded via ECoG [76]. Similarly, wireless microscale ECoG neural probes have been used to investigate reach-and-grasp movements in non-human primates [77]. In addition, Chang and Chiou developed a chronic ECoG system that can be used to measure neural activity without communicating wires or batteries [78]. Such findings suggest that this type of neural probe can be integrated not only in freely moving animals, but also in humans.

Based on our review of studies involving high-performance ECoG with a large number of channels, we conclude that ECoG would be advantageous in BMI applications due to its relatively low level of invasiveness [79] and the potential for long-term LFP recording [80]. In addition, ECoG electrodes can be applied to brain regions of various shapes, enabling the application of BMI systems for various functions $[74,75]$. We expect that advances in ECoG electrodes will further facilitate BMI applications.

\section{Injectable neural probe}

Some research groups have introduced flexible, syringe-inject- able electronic devices for the measurement of chronic in vivo neural activity (Fig. 5B) [81]. To establish injectable neural probes, Liu et al. applied nanotechnology-based fabrication techniques to develop electronics composed of flexible mesh [82, 83]. Injectable mesh electronics can be produced via multiple fabrication techniques such as photolithography, which can be used to define the structures and regions of nanoscale silicon wires, metal deposition, and in the chemical development of nanostructures [82-85]. One preliminary study revealed that such devices could be used to record neural activity in freely moving mice [86]. The mesh recording electrodes has less invasiveness compared to other counterpart implantable probes due to their microscale size and high flexibility. If the biocompatibility and quality of acquired neural signals can be secured in the future, we believe that the injectable neural probe offers a better alternative for detecting brain activity in various BMI applications.

\section{Stent electrodes array}

A stent is a medical tube that can be implanted into the vessels to maintain an opening for blood flow. Stents are widely utilized in the treatment of arteriosclerosis since its appearance [87], as they are significantly less invasive than traditional methods [88, 89]. To achieve minimal invasiveness and long-term biocompatibility, Oxley et al. developed an endovascular stent-electrode array, as pictured in Fig. 5C [90]. Stent-electrode arrays can be installed by inserting a catheter into the appropriate cerebral blood vessel. Accurate induction of each electrode array position can be acquired using x-ray angiographic fluorography. One preclinical study reported that stent-electrode arrays with multiple neural probes could be used for the long-term measurement of somatosensory evoked potentials in the sheep brain. The feasibility and sustainable biocompatibility of long-term/chronic neural interfaces in brain blood vessels have been confirmed via $\mathrm{x}$-ray micro-tomography and histological assays [91]. Recent studies have demonstrated that endovascular stent-electrode arrays can be used to acquire vascular ECoG signals [92] and detect electrochemical changes via impedance spectroscopy [93]. Despite such advancements, no studies have demonstrated that state-of-the-art stent electrodes can provide immediately usable neural signals (e.g., movement-related activity) for BMI applications. Nonetheless, researchers have successfully acquired somatosensory evoked potentials from stent electrodes implanted in the superficial cortical vein overlying the motor cortex in sheep via catheter angiography [90]. Therefore, future studies may be able to harness movementrelated information conveyed to stent electrodes to enhance BMI development. 


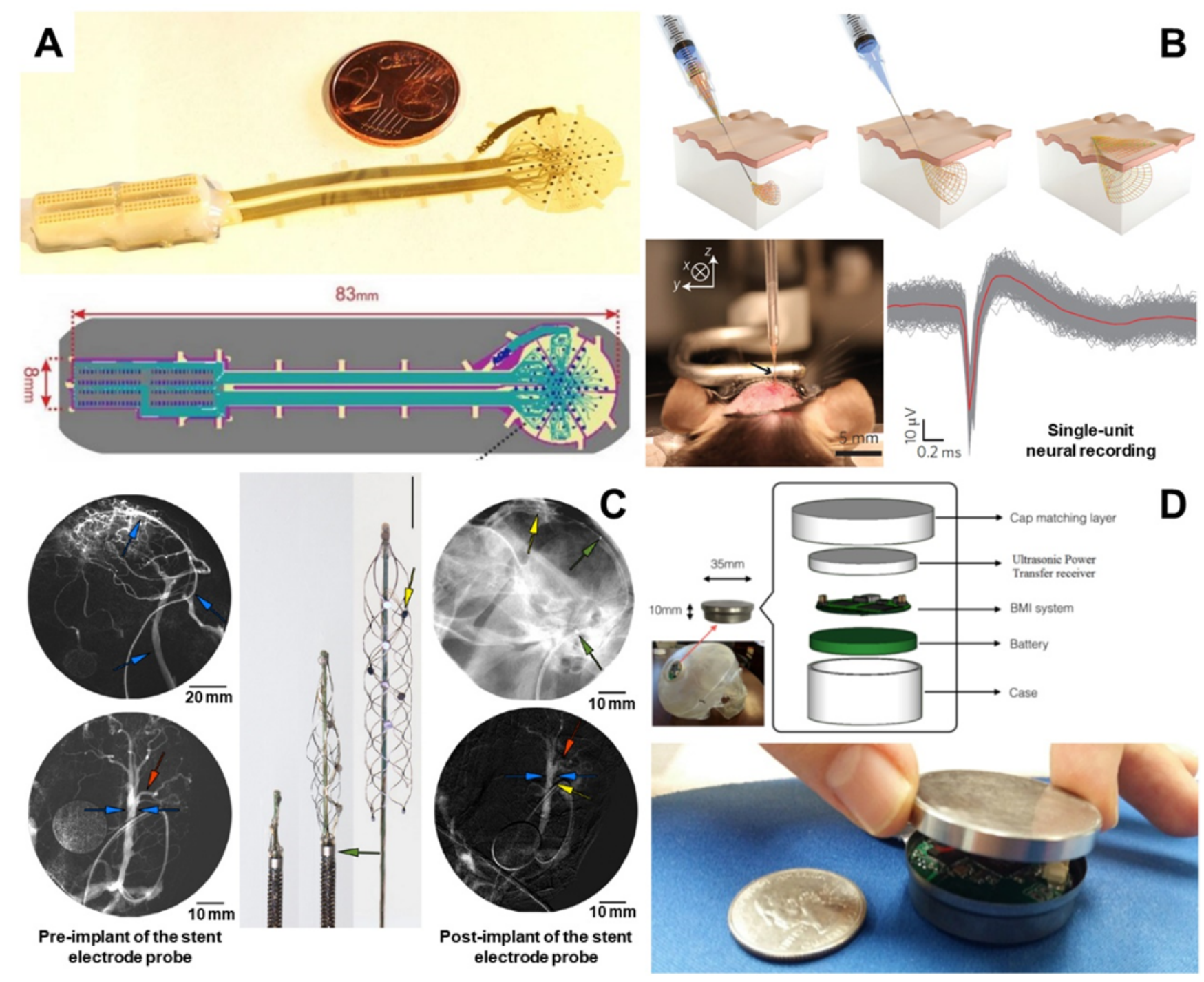

Fig. 5. (A) A flex-rigid 124-channel ECoG electrode array to measure neural activities. This neural probe was manufactured with advanced and highresolution microscale fabrication techniques. This figure in [75] is reprinted with a permission of MDPI, Basel, Switzerland under the terms and conditions of the Creative Commons Attribution License. (B) Implant procedures, in vivo insertion and single-unit neural recording of an injectable neural probe. The re-use of this figure published in [81] was approved by Nature Publishing Group (Springer Nature). (C) A stent electrode array (middle) with 8 electrodes to acquire neural signals in the brain vessel and pre- and post-implant images in a delivery of the stent electrode array by X-ray venography. This figure published in [90] is reprinted with a permission of Nature Publishing Group (Springer Nature). (D) An implantable wireless implantable recording and stimulating probe for bidirectional BMI instruments. The reprint of this figure in [96] was permitted by MDPI, Basel, Switzerland under the terms and conditions of the Creative Commons Attribution License.

\section{Wireless neural probes for BMIs}

The use of physical wires inside the brain to acquire neural signals is associated with several disadvantages, such as the risk of infection and reduced freedom of movement. To overcome these shortcomings, researchers have investigated the application of wireless neural recording techniques to BMI systems. For instance, Schwarz et al. developed a wireless multi-channel platform for monitoring neural activity, which was applied successfully in freely moving non-human primates [94]. This system, which resembles a crown, consists of hundreds to thousands of microwire electrodes, a wireless recording/transmitting module, and a battery. In addition, the same research group introduced a wheelchair robot that could be controlled based on neural activity recorded wirelessly from an onboard monkey [95]. Similarly, Libedinsky et al. investigated the application of a robotic vehicle independently moved by neural signals using a 100-channel wireless probe. Su et al. introduced a wireless implantable recording/stimulating probe for bidirectional BMIs, as described in Fig. 5D [96]. This latter probe is 
advantageous due to its small size and ability for remote charging.

Researchers have also investigated the application of ultrasound technology as a carrier of neural signals from medium-depth tissue. Such "neural dust" systems are advantageous in that they are able to send and receive information non-invasively in certain areas of the brain. Seo et al. investigated a neural dust system consisting of recording electrodes, a piezoelectric ultrasound generator, drive electrodes, and a wireless cortical recording platform [97]. In this system, an external ultrasound probe sends out an echo with a specific waveform, following which a reflected wave (i.e., neural signal) is emitted from the system. This neural signal can be isolated by examining the specific waveform transmitted and the backscattered signal. Preliminary studies designed to measure neural activity in the peripheral nervous system using a neural dust system in rats have demonstrated the potential of these systems for application in BMI technologies.

We anticipate that advancements in the following areas will promote the use of wireless neural electrodes in practical BMI applications: ultra-low power consumption, high signal-to-noise ratio, sufficient maximum communication distance for receiving and transmitting data, and channel number [76, 98]. Furthermore, wireless BMI systems must be designed to prevent malfunctions by erasing noise from the external environment, to have an efficient means of changing the battery, and to function for a long period of time on single charge $[99,100]$.

\section{MULTI-MODAL NEURAL PROBES TO MEASURE BOTH ELEC- TRICAL AND OPTICAL SIGNALS}

While direct electrical measurements can be obtained using implantable neural probes as described in previous sections, optical measurement methods are also utilized to record neural activity at the level of single neurons and neuronal assemblies. Optical methods rely on indices such as the influx of calcium ions $\left(\mathrm{Ca}^{2+}\right)$ and changes in voltage. Since changes in $\mathrm{Ca}^{2+}$ can represent neural activity, several optical indicators have been applied in studies ranging from in vitro cellular assays $[101,102]$ to in vivo investigations in freely moving animals [103]: a bioluminescent $\mathrm{Ca}^{2+}$ probing protein (Aequorin) [104], chemical $\mathrm{Ca}^{2+}$ indicators (calcium green, fura-2 etc.) $[105,106]$, genetically encoded $\mathrm{Ca}^{2+}$ indicators based on a single fluorophore [107] and Förster resonance energy transfer (FRET) [108]. In addition, voltage-sensitive optical dyes can be used to identify transient changes in action potentials in neurons [109-111]. In addition, voltage-sensitive optical dyes can be used to identify transient changes in action potentials in neurons. Indeed, researchers have developed optical implantable neural probes for use in freely behaving animals by combining fiberoptic and wireless communication technologies. For instance, Murayama et al. designed a miniaturized neuro-endoscopic periscope using graded-index (GRIN) lenses and micro-prism coupled fibers. This periscope was used to study dendritic $\mathrm{Ca}^{2+}$ changes in freely moving mice [112]. Ghosh et al. introduced a prototype of a miniaturized wide-field fluorescence microscope with which they could measure neural activity when the device was mounted on the head of freely moving animals [113]. Besides, optical neuro-stimulations were exercised since the discovery of optogenetics stimulation. Furthermore, optical devices can be used for stimulation purposes as well: In the case of Channelrhodopsin (ChR), trans-membrane pores are opened when ChR-integrated ion channels absorb blue light at a wavelength of $470 \mathrm{~nm}$, causing ions to flow into the neurons [114-116]. Preclinical studies have confirmed that fiber-coupled illumination devices function well in freely moving animals. Aravanis et al. designed a fiber-coupled optical neural interface guided by ChR2-mCherry fluorescence images for use in rats [117]. Several research groups have also developed prototypes of wirelessly integrated LED-based implantable neural stimulation modules for use in freely moving animals [118-120].

Electrical and optical signals can be measured without interference from one another because their frequency domains are different. For this reason, several prototypes of multi-modal neural probes have been developed to measure both electrical and optical activity in preclinical studies $[121,122]$. LeChasseur et al. developed a micro-probe, which consists of a dual-core optical fiber and a $50-\mu \mathrm{m}$ electrical wire probe for recording both electrical and optical neural activities, as illustrated in Fig. 6A [123]. In a comparative study, the authors recorded optical and electrical neural signals from the same neuron in rats, observing that the two modalities were complementary and highly correlated with one another. Anikeeva et al. developed an optetrode, which is composed of a 200- $\mu \mathrm{m}$ single-channel optical fiber and a tetrode, to investigate optical stimulation and neural responses (recorded by the tetrode), as described in Fig. 6B [124]. The optetrode detected multi-unit neural activity and transient changes when optical stimulation was provided at different frequencies. Voigts et al. investigated an ultralight weight neural probe (i.e., FlexDrive) consisting of a singlecore optical fiber and 16,32, or 64-channel electrodes for studies of multi-dimensional neural responses to optogenetic stimulation [125]. Kwon and colleagues combined a transparent ECoG electrode array and an optical illumination device for optogenetic stimulation [126]. In another preliminary in vivo study, the authors proposed a prototype of a multi-modal neural probe termed the Opto- $\mu \mathrm{ECoG}$ array, which exhibits sufficient biocompatibility. Several researchers have also introduced variations of the Utah 

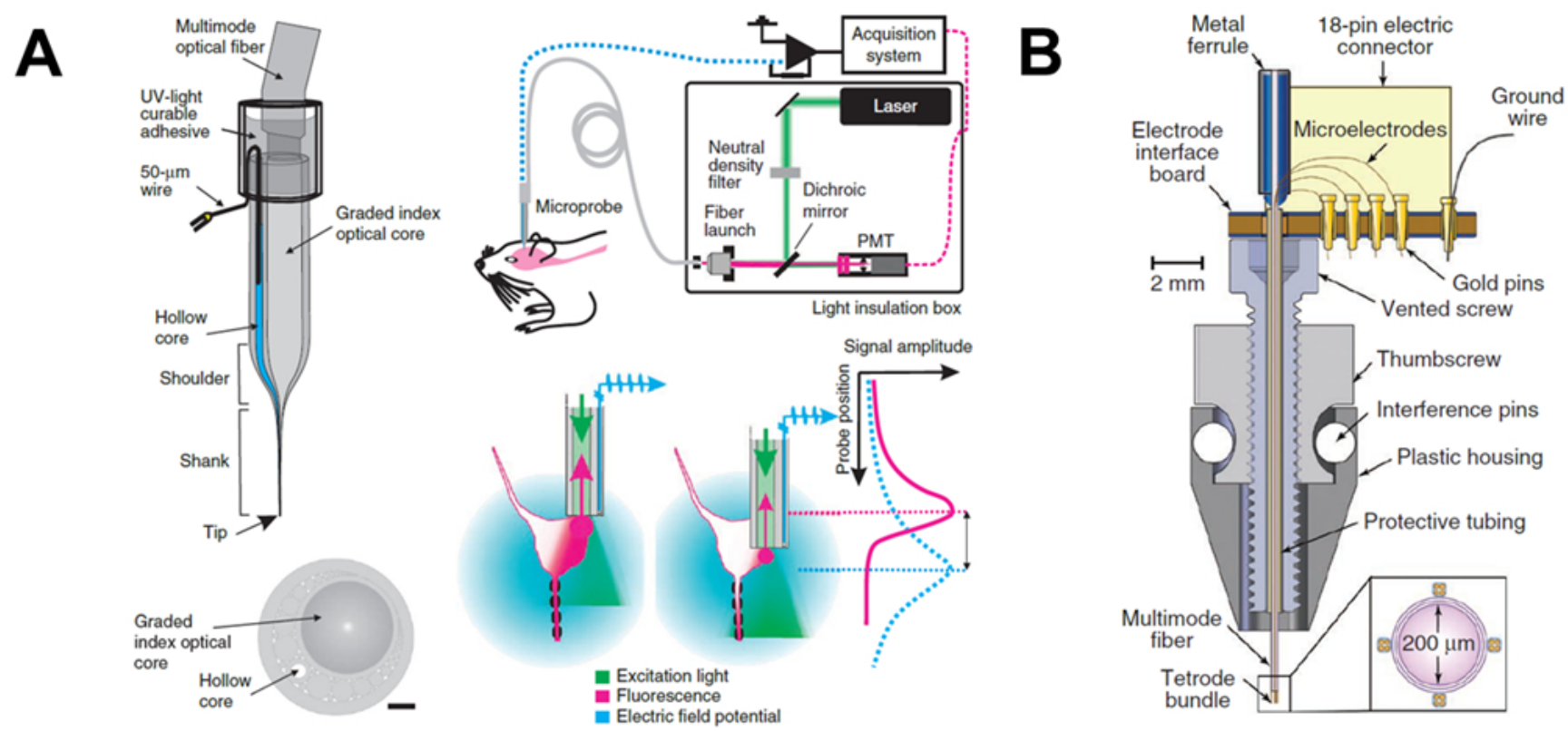

Fig. 6. (A) A multimodal microprobe with optical and electrical measurements of neural activities. The multimodal probe consisted of a dual-core optical fiber, which excited fluorescent indicators and collected emitted signals, and an electrical wire to record electrical activities in neurons. This figure in [123] is reprinted with a permission of Nature Publishing Group (Springer Nature). (B) A schematic of an optetrode, which consisted of a single optical fiber with $200 \mu \mathrm{m}$ core diameters for optogenetic stimulations and a tetrode to record neural activities and changes when the optical stimulation occurs. The re-use of this figure published in [124] was approved by Nature Publishing Group (Springer Nature).

array combined with miniaturized optical components to acquire high-resolution electrical neural signals following optical neurostimulation $[127,128]$. Similarly, previous studies have reported the success of BMI systems based on optogenetic neuromodulation and electrical neural recordings in small animals [129-135]. For example, Liu et al. developed a compact optogenetics system using graphene electrodes to reduce artifacts [136]. We expect that multi-modal BMI systems will evolve toward more specific applications when the safety and stability of both probes have been demonstrated.

Based on previous research, we expect the following benefits to be associated with the use of multi-modal neural probes that combine optical and electrophysiological modalities in BMI systems. When using neural probes to record both optical and electrical neural signals, cross-validation of fidelity between the two signals can increase signal reliability. In particular, since the noise sources of the two signals are likely to be different, one signal can be used when another signal is perturbed. In the context of BMI applications, multi-modal probes may be useful when the patient is in an electromagnetically noisy environment. Such probes may also be advantageous for advanced BMI systems that require precise stimulation and minimal interference between signals. However, few optogenetic genes have been identified and cleared for use in humans due to safety concerns $[137,138]$. Genetic engineering remains quite challenging due to its unknown long-term impact on humans, although it is expected that these technologies will be utilized in various BMI systems once issues regarding safety and stability have been addressed.

\section{NEURAL PROBES WITH ADVANCED MATERIALS}

In order for successful implantation in the human brain, neural probes must exhibit sufficient biocompatibility, safety, stability, and electrical performance. However, electrodes composed of classic materials such as iridium oxide and platinum are limited in their ability to meet these conditions. To overcome these limitations, advanced materials with special functions and properties including metals, inorganic materials, and polymers have been applied to the development of neural probes.

Carbon nanotubes (CNTs) are cylindrically structured allotropes of carbon that are stronger and have better elasticity and electrical properties than more traditional materials [139, 140]. As such, various studies have aimed to develop neural probes using CNTs. Wang et al. designed a microelectrode array composed of CNTs, reporting significant improvements in the charge injection limit when CNT electrodes were used to stimulate cultured hippocampal neurons [141]. Keefer et al. developed a CNT coating to enhance charge transfer in microelectrode arrays [142]. In this study, 
the authors obtained stronger neural activity from CNT-coated electrodes in the primate visual cortex, with an improvement factor of $7.4 \mathrm{~dB}$ (Fig. 7A). Guitchounts et al. developed 16-channel carbon fiber neural probes with which they could acquire longterm chronic neural signals due to the strength and stability of the carbon fiber [143]. In addition, previous studies have demonstrated the successful integration of a soft CNT fiber microelectrode array in long-term bidirectional neural interfaces. Such findings suggest that this system can be used to develop high-performance and biocompatible BMI devices and neuroprosthetic instruments [144]. Graphene, a two-dimensional carbon allotrope, can also be utilized to improve the performance of neural probes due to its mechanical stiffness, flexibility, and superior electrical properties [145]. For instance, Chen et al. designed flexible graphene microprobes that can be applied to record electrical signals associated with neural or cardiac activity [146]. Graphene-based flexible electrodes have also been fabricated to acquire ECoG signals by improving contact with the brain. Additional studies have indicated that graphene can be used to investigate changes in neural activity due to optogenetic stimulation due to its high transparency [147]. Similarly, Kuzum et al. developed a graphene electrode array with high flexibility and transparency: They acquired electrical neural signals and fluorescence images indicating changes in calcium flux using the same electrode [148]. Furthermore, graphene-based electrodes can be integrated into multi-functional neural probes. For instance, Liu et al. introduced neural probes that consist of graphene-oxide and gold-oxide electrodes, as illustrated in Fig.
7B [149]. This novel probe can be used to obtain measurements of both electrophysiological neural signals and electrochemical information via cyclic voltammetry. Indeed, this type of electrode can be used to monitor neural activity and various electrochemical changes after the induction of brain damage due to photo-thrombosis. Apollo et al. also investigated the application of needle-type flexible neural probes made from graphene oxide for use in bidirectional neural interfaces [150].

Due to the development of efficient techniques for fabricating and manufacturing nanoscale structures and particles, nanotechnology has quickly become relevant to biological and biomedical applications Indeed, nanoscale structures and particles have been applied to improve neural probes. Park et al. developed a nanoporous platinum electrode that can be used to record neural signals [151]. In this study, the authors reported that the nanoporous electrodes were associated with improvements in electrical properties, impedance, and charge injection limits when compared with commercially available alternatives such as platinized platinum and iridium oxide electrodes. Other studies have demonstrated the enhanced biocompatibility of gallium phosphide nanowire electrodes [152]. These nanowire electrodes were tested in the rat primary somatosensory cortex. Abidian and colleagues introduced nanostructured polymer-coated conducting electrodes with enhanced electrical properties, improved mechanical adhesion, and better neuronal attachment capabilities [153]. Piret et al. developed boron-doped diamond electrodes with three dimensionally fabricated nanostructures using multiple semiconductor fabrication
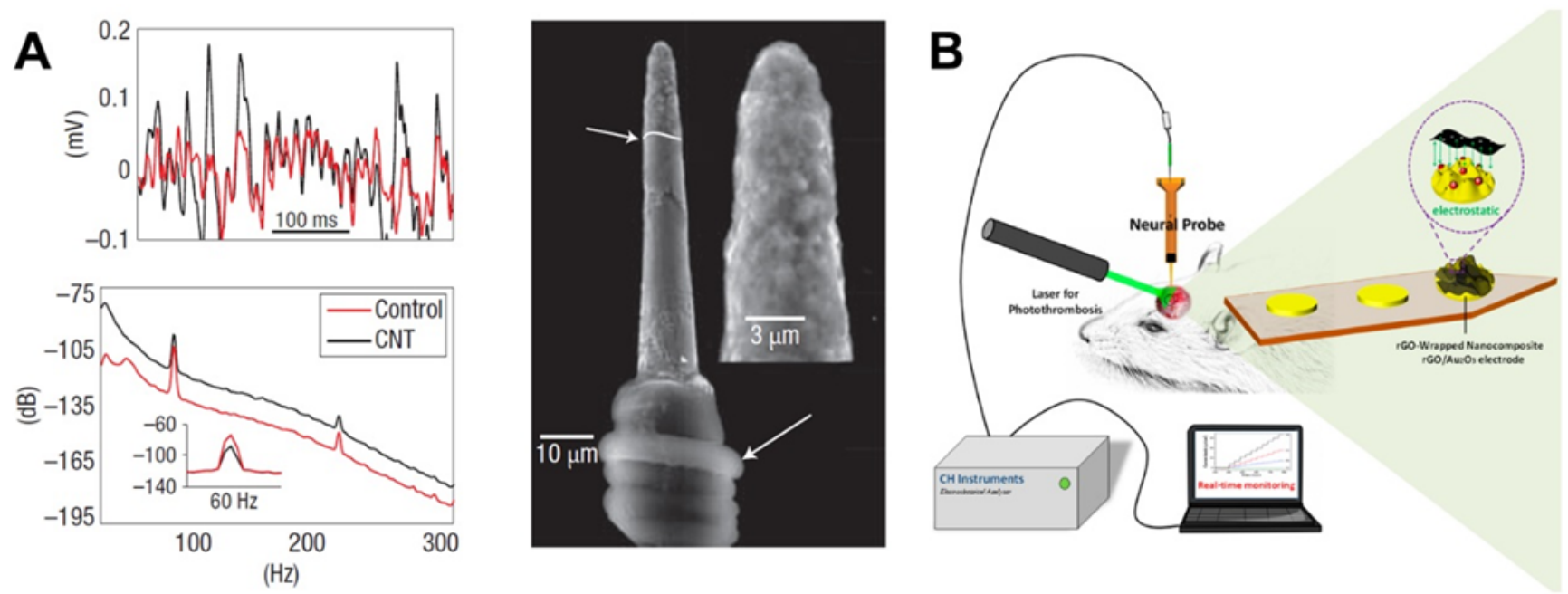

Fig. 7. (A) Carbon nanotubes coated microelectrode arrays to improve electrical property in recording neural activities. Left plots illustrates local field potential and power spectral density with frequencies in ranging from 1 to $300 \mathrm{~Hz}$ comparing microelectrodes coated with carbon nanotube to ones without coating. The reprint of this figure in [142] was permitted by Nature Publishing Group (Springer Nature). (B) A schematic of in vivo experimental setup in a study recording neural activities and electrochemical changes during photo-thrombosis. The neural probes used in this setup consist of graphene-oxide and gold-oxide combined electrodes. The figure published in [149] is reprinted with a permission of American Chemical Society. 
techniques [154]. Relative to conventional boron-doped diamond electrodes, the nanostructured electrodes offer higher sensitivity to neural activity while maintaining stability and biocompatibility, suggesting that these electrodes can be applied in the development of highly sensitive BMI systems and rehabilitation instruments.

\section{CONCLUSIONS}

In this report, we have reviewed the application of current multichannel neural probes (i.e., the tetrode, Utah array, and Michigan probe) to BMI systems, as well as developments regarding nextgeneration neural probes. When comparing the electrodes currently in use, it is important to choose the proper neural probe based on the function and purpose of the BMI application. For instance, for measurement and stimulation of pyramidal neurons in deep sulcus areas-which are known to directly control fine muscles such as those in the hand-a neural probe with a longer shank is required. We also discussed several developing neural probes, which aim to improve upon the electrical properties, biocompatibility, and reliability of current devices using multi-modal approaches. If high-density electrodes with improved biocompatibility can be developed, flexible ECoG systems can be more widely applied in both clinical and preclinical BMI studies. Although stent electrodes are currently at the proof-of-concept stage, their minimal invasiveness suggests that they can replace many other methods for acquiring neural signals in the future. Safety concerns represent the greatest challenge for BMI systems based on optogenetic stimulation. The application of new materials, high-resolution integrated technologies, and nanotechnology will ultimately contribute to the development of high-performance neural probes and BMI systems.

While the long-term fidelity of neural recordings is critical for success in BMI systems, several subsequent stages of processing are critical for ensuring the efficiency of these systems (Fig. 1). Decoding algorithms that allow for accurate analysis of acquired neural signals and encoding techniques that transfer outward information to the brain are also important components of a BMI system [155-158]. High-speed computing and wireless signal processing are also critical for the development of high-performance BMI systems that can be applied in real-world settings.

Perhaps the most important issue facing developers is the biocompatibility and mechanical suitability of implantable neural probes. Advancements in material science and mechanical techniques will aid in developing strategies for minimizing brain scarring while maintaining adequate electrode contact $[159,160]$. Assessments of signal quality and side effects should be performed in both in vitro and in vivo systems (e.g., non-human primates) to determine the practical applications of novel BMI systems prior to use in humans. For these reasons, it is also necessary to choose appropriate packaging techniques to enhance the biocompatibility of implantable neural probes.

Mass production and security concerns should also be addressed in the development of neural probes for commercial and realworld use. Because the electrode is inserted into the brain, proper mass manufacturing technologies are required, without sacrificing the quality of the probe from production to packaging. Thus, systematic inspection methods should also develop. Several security experts have cautioned that information leakage may occur when using BMI systems $[161,162]$. Therefore, establishing technologies to prevent information leakage is another issue that must be addressed when considering the practical applications of BMI systems. In conjunction with technological advancements, consensus regarding social and ethical concerns will lead to widespread utilization of implantable neural probes and BMI systems.

\section{ACKNOWLEDGEMENTS}

This research was supported by grants of the Brain Research Program through the National Research Foundation of Korea (NRF) funded by the Ministry of Science and ICT (2016M3C7A1904986).

\section{REFERENCES}

1. Nair P (2013) Brain-machine interface. Proc Natl Acad Sci U SA 110:18343.

2. Fetz EE (2015) Restoring motor function with bidirectional neural interfaces. Prog Brain Res 218:241-252.

3. Merritt B (2016) The digital revolution. In: Synthesis lectures on emerging engineering technologies (Iniewski K, ed), pp 1-109. Morgan \& Claypool Publishers, San Rafael, CA.

4. Patil PG, Turner DA (2008) The development of brain-machine interface neuroprosthetic devices. Neurotherapeutics 5:137-146.

5. Bell CJ, Shenoy P, Chalodhorn R, Rao RP (2008) Control of a humanoid robot by a noninvasive brain-computer interface in humans. J Neural Eng 5:214-220.

6. Kansaku K, Hata N, Takano K (2010) My thoughts through a robot's eyes: an augmented reality-brain-machine interface. Neurosci Res 66:219-222.

7. Miranda RA, Casebeer WD, Hein AM, Judy JW, Krotkov EP, Laabs TL, Manzo JE, Pankratz KG, Pratt GA, Sanchez JC, Weber DJ, Wheeler TL, Ling GS (2015) DARPA-funded efforts in the development of novel brain-computer interface technolo- 
gies. J Neurosci Methods 244:52-67.

8. Panzeri S, Safaai H, De Feo V, Vato A (2016) Implications of the dependence of neuronal activity on neural network states for the design of brain-machine interfaces. Front Neurosci 10:165.

9. Millán Jdel R, Renkens F, Mouriño J, Gerstner W (2004) Noninvasive brain-actuated control of a mobile robot by human EEG. IEEE Trans Biomed Eng 51:1026-1033.

10. Rebsamen B, Guan C, Zhang H, Wang C, Teo C, Ang MH Jr, Burdet E (2010) A brain controlled wheelchair to navigate in familiar environments. IEEE Trans Neural Syst Rehabil Eng 18:590-598.

11. Müller KR, Tangermann M, Dornhege G, Krauledat M, Curio G, Blankertz B (2008) Machine learning for real-time singletrial EEG-analysis: from brain-computer interfacing to mental state monitoring. J Neurosci Methods 167:82-90.

12. Fazli S, Mehnert J, Steinbrink J, Curio G, Villringer A, Müller KR, Blankertz B (2012) Enhanced performance by a hybrid NIRS-EEG brain computer interface. Neuroimage 59:519529.

13. Coyle SM, Ward TE, Markham CM (2007) Brain-computer interface using a simplified functional near-infrared spectroscopy system. J Neural Eng 4:219-226.

14. Kauhanen L, Nykopp T, Lehtonen J, Jylänki P, Heikkonen J, Rantanen P, Alaranta H, Sams M (2006) EEG and MEG brain-computer interface for tetraplegic patients. IEEE Trans Neural Syst Rehabil Eng 14:190-193.

15. Yeom HG, Kim JS, Chung CK (2013) Estimation of the velocity and trajectory of three-dimensional reaching movements from non-invasive magnetoencephalography signals. J Neural Eng 10:026006.

16. Iturrate I, Antelis JM, Kubler A, Minguez J (2009) A noninvasive brain-actuated wheelchair based on a P300 neurophysiological protocol and automated navigation. IEEE Trans Robot 25:614-627.

17. Waldert S (2016) Invasive vs. non-invasive neuronal signals for brain-machine interfaces: will one prevail? Front Neurosci 10:295.

18. Wodlinger B, Downey JE, Tyler-Kabara EC, Schwartz AB, Boninger ML, Collinger JL (2015) Ten-dimensional anthropomorphic arm control in a human brain-machine interface: difficulties, solutions, and limitations. J Neural Eng 12:016011.

19. Baranauskas G (2014) What limits the performance of current invasive brain machine interfaces? Front Syst Neurosci $8: 68$.

20. Georgopoulos AP, Schwartz AB, Kettner RE (1986) Neuronal population coding of movement direction. Science 233:1416-
1419.

21. Adrian ED, Bronk DW (1929) The discharge of impulses in motor nerve fibres: part II. The frequency of discharge in reflex and voluntary contractions. J Physiol 67:i3-i151.

22. Ling G, Gerard RW (1949) The normal membrane potential of frog sartorius fibers. J Cell Comp Physiol 34:383-396.

23. Bretag AH (2017) The glass micropipette electrode: a history of its inventors and users to 1950. J Gen Physiol 149:417-430.

24. Henze DA, Borhegyi Z, Csicsvari J, Mamiya A, Harris KD, Buzsáki G (2000) Intracellular features predicted by extracellular recordings in the hippocampus in vivo. J Neurophysiol 84:390-400.

25. Holmgren C, Harkany T, Svennenfors B, Zilberter Y (2003) Pyramidal cell communication within local networks in layer 2/3 of rat neocortex. J Physiol 551:139-153.

26. Buzsáki G (2004) Large-scale recording of neuronal ensembles. Nat Neurosci 7:446-451.

27. Takahashi S, Anzai Y, Sakurai Y (2003) A new approach to spike sorting for multi-neuronal activities recorded with a tetrode--how ICA can be practical. Neurosci Res 46:265-272.

28. Gray CM, Maldonado PE, Wilson M, McNaughton B (1995) Tetrodes markedly improve the reliability and yield of multiple single-unit isolation from multi-unit recordings in cat striate cortex. J Neurosci Methods 63:43-54.

29. Shoham S, Fellows MR, Normann RA (2003) Robust, automatic spike sorting using mixtures of multivariate t-distributions. J Neurosci Methods 127:111-122.

30. Nguyen DP, Layton SP, Hale G, Gomperts SN, Davidson TJ, Kloosterman F, Wilson MA (2009) Micro-drive array for chronic in vivo recording: tetrode assembly. J Vis Exp 26:1098.

31. Xie K, Fox GE, Liu J, Tsien JZ (2016) 512-channel and 13-region simultaneous recordings coupled with optogenetic manipulation in freely behaving mice. Front Syst Neurosci 10:48.

32. Giszter SF, Hart CB, Udoekwere UI, Markin S, Barbe C (2005) A real-time system for small animal neurorobotics at spinal or cortical levels. Int IEEE EMBS Conf Neural Eng 2005:450453.

33. Song W, Ramakrishnan A, Udoekwere UI, Giszter SF (2009) Multiple types of movement-related information encoded in hindlimb/trunk cortex in rats and potentially available for brain-machine interface controls. IEEE Trans Biomed Eng 56:2712-2716.

34. Song W, Giszter SF (2011) Adaptation to a cortex-controlled robot attached at the pelvis and engaged during locomotion in rats. J Neurosci 31:3110-3128.

35. Bender JA, Pollack AJ, Ritzmann RE (2010) Neural activity in the central complex of the insect brain is linked to locomotor 
changes. Curr Biol 20:921-926.

36. Oweiss KG (2006) A systems approach for data compression and latency reduction in cortically controlled brain machine interfaces. IEEE Trans Biomed Eng 53:1364-1377.

37. Kubo T, Katayama N, Karashima A, Nakao M (2008) The 3D position estimation of neurons in the hippocampus based on the multi-site multi-unit recordings with silicon tetrodes. Conf Proc IEEE Eng Med Biol Soc 2008:5021-5024.

38. Campbell PK, Jones KE, Huber RJ, Horch KW, Normann RA (1991) A silicon-based, three-dimensional neural interface: manufacturing processes for an intracortical electrode array. IEEE Trans Biomed Eng 38:758-768.

39. Velliste M, Perel S, Spalding MC, Whitford AS, Schwartz AB (2008) Cortical control of a prosthetic arm for self-feeding. Nature 453:1098-1101.

40. Chase SM, Kass RE, Schwartz AB (2012) Behavioral and neural correlates of visuomotor adaptation observed through a brain-computer interface in primary motor cortex. J Neurophysiol 108:624-644.

41. Capogrosso M, Milekovic T, Borton D, Wagner F, Moraud EM, Mignardot JB, Buse N, Gandar J, Barraud Q, Xing D, Rey E, Duis S, Jianzhong Y, Ko WK, Li Q, Detemple P, Denison T, Micera S, Bezard E, Bloch J, Courtine G (2016) A brain-spine interface alleviating gait deficits after spinal cord injury in primates. Nature 539:284-288.

42. Tabot GA, Dammann JF, Berg JA, Tenore FV, Boback JL, Vogelstein RJ, Bensmaia SJ (2013) Restoring the sense of touch with a prosthetic hand through a brain interface. Proc Natl Acad Sci U S A 110:18279-18284.

43. Kim S, Callier T, Tabot GA, Gaunt RA, Tenore FV, Bensmaia SJ (2015) Behavioral assessment of sensitivity to intracortical microstimulation of primate somatosensory cortex. Proc Natl Acad Sci U S A 112:15202-15207.

44. Suner S, Fellows MR, Vargas-Irwin C, Nakata GK, Donoghue JP (2005) Reliability of signals from a chronically implanted, silicon-based electrode array in non-human primate primary motor cortex. IEEE Trans Neural Syst Rehabil Eng 13:524541.

45. Simeral JD, Kim SP, Black MJ, Donoghue JP, Hochberg LR (2011) Neural control of cursor trajectory and click by a human with tetraplegia 1000 days after implant of an intracortical microelectrode array. J Neural Eng 8:025027.

46. Pandarinath C, Gilja V, Blabe CH, Nuyujukian P, Sarma AA, Sorice BL, Eskandar EN, Hochberg LR, Henderson JM, Shenoy KV (2015) Neural population dynamics in human motor cortex during movements in people with ALS. Elife 4:e07436.

47. Gilja V, Pandarinath C, Blabe CH, Nuyujukian P, Simeral JD,
Sarma AA, Sorice BL, Perge JA, Jarosiewicz B, Hochberg LR, Shenoy KV, Henderson JM (2015) Clinical translation of a high-performance neural prosthesis. Nat Med 21:1142-1145.

48. Jarosiewicz B, Sarma AA, Bacher D, Masse NY, Simeral JD, Sorice B, Oakley EM, Blabe C, Pandarinath C, Gilja V, Cash SS, Eskandar EN, Friehs G, Henderson JM, Shenoy KV, Donoghue JP, Hochberg LR (2015) Virtual typing by people with tetraplegia using a self-calibrating intracortical braincomputer interface. Sci Transl Med 7:313ral79.

49. Wodlinger B, Downey JE, Tyler-Kabara EC, Schwartz AB, Boninger ML, Collinger JL (2015) Ten-dimensional anthropomorphic arm control in a human brain-machine interface: difficulties, solutions, and limitations. J Neural Eng 12:016011.

50. Bouton CE, Shaikhouni A, Annetta NV, Bockbrader MA, Friedenberg DA, Nielson DM, Sharma G, Sederberg PB, Glenn BC, Mysiw WJ, Morgan AG, Deogaonkar M, Rezai AR (2016) Restoring cortical control of functional movement in a human with quadriplegia. Nature 533:247-250.

51. Ajiboye AB, Willett FR, Young DR, Memberg WD, Murphy BA, Miller JP, Walter BL, Sweet JA, Hoyen HA, Keith MW, Peckham PH, Simeral JD, Donoghue JP, Hochberg LR, Kirsch RF (2017) Restoration of reaching and grasping movements through brain-controlled muscle stimulation in a person with tetraplegia: a proof-of-concept demonstration. Lancet 389:1821-1830.

52. Flesher SN, Collinger JL, Foldes ST, Weiss JM, Downey JE, Tyler-Kabara EC, Bensmaia SJ, Schwartz AB, Boninger ML, Gaunt RA (2016) Intracortical microstimulation of human somatosensory cortex. Sci Transl Med 8:361ra141.

53. Normann RA (2007) Technology insight: future neuroprosthetic therapies for disorders of the nervous system. Nat Clin Pract Neurol 3:444-452.

54. Wark HA, Sharma R, Mathews KS, Fernandez E, Yoo J, Christensen B, Tresco P, Rieth L, Solzbacher F, Normann RA, Tathireddy P (2013) A new high-density (25 electrodes $/ \mathrm{mm}^{2}$ ) penetrating microelectrode array for recording and stimulating sub-millimeter neuroanatomical structures. J Neural Eng 10:045003.

55. Pochay P, Wise KD, Allard LF, Rutledge LT (1979) A multichannel depth probe fabricated using electron-beam lithography. IEEE Trans Biomed Eng 26:199-206.

56. Vetter RJ, Otto KJ, Marzullo TC, Kipke DR (2003) Brainmachine interfaces in rat motor cortex: neuronal operant conditioning to perform a sensory detection task. Int IEEE EMBS Conf Neural Eng 2003:637-640.

57. Kipke DR, Vetter RJ, Williams JC, Hetke JF (2003) Siliconsubstrate intracortical microelectrode arrays for long-term 
recording of neuronal spike activity in cerebral cortex. IEEE Trans Neural Syst Rehabil Eng 11:151-155.

58. Vetter RJ, Williams JC, Hetke JF, Nunamaker EA, Kipke DR (2004) Chronic neural recording using silicon-substrate microelectrode arrays implanted in cerebral cortex. IEEE Trans Biomed Eng 51:896-904.

59. Frost SB, Dunham CL, Barbay S, Krizsan-Agbas D, Winter MK, Guggenmos DJ, Nudo RJ (2015) Output properties of the cortical hindlimb motor area in spinal cord-injured rats. J Neurotrauma 32:1666-1673.

60. Guggenmos DJ, Azin M, Barbay S, Mahnken JD, Dunham C, Mohseni P, Nudo RJ (2013) Restoration of function after brain damage using a neural prosthesis. Proc Natl Acad Sci U S A 110:21177-21182.

61. Barz F, Livi A, Lanzilotto M, Maranesi M, Bonini L, Paul O, Ruther P (2017) Versatile, modular 3D microelectrode arrays for neuronal ensemble recordings: from design to fabrication, assembly, and functional validation in non-human primates. J Neural Eng 14:036010.

62. Schalk G, Leuthardt EC (2011) Brain-computer interfaces using electrocorticographic signals. IEEE Rev Biomed Eng 4:140-154.

63. Pistohl T, Ball T, Schulze-Bonhage A, Aertsen A, Mehring C (2008) Prediction of arm movement trajectories from ECoGrecordings in humans. J Neurosci Methods 167:105-114.

64. Chao ZC, Nagasaka Y, Fujii N (2010) Long-term asynchronous decoding of arm motion using electrocorticographic signals in monkeys. Front Neuroeng 3:3.

65. Rouse AG, Williams JJ, Wheeler JJ, Moran DW (2016) Spatial co-adaptation of cortical control columns in a micro-ECoG brain-computer interface. J Neural Eng 13:056018.

66. Ryun S, Kim JS, Lee H, Chung CK (2017) Tactile frequencyspecific high-gamma activities in human primary and secondary somatosensory cortices. Sci Rep 7:15442.

67. Wang W, Degenhart AD, Collinger JL, Vinjamuri R, Sudre GP, Adelson PD, Holder DL, Leuthardt EC, Moran DW, Boninger ML, Schwartz AB, Crammond DJ, Tyler-Kabara EC, Weber DJ (2009) Human motor cortical activity recorded with MicroECoG electrodes, during individual finger movements. Conf Proc IEEE Eng Med Biol Soc 2009:586-589.

68. Wang W, Collinger JL, Degenhart AD, Tyler-Kabara EC, Schwartz AB, Moran DW, Weber DJ, Wodlinger B, Vinjamuri RK, Ashmore RC, Kelly JW, Boninger ML (2013) An electrocorticographic brain interface in an individual with Tetraplegia. PLoS One 8:e55344.

69. Shin D, Watanabe H, Kambara H, Nambu A, Isa T, Nishimura Y, Koike Y (2012) Prediction of muscle activities from electro- corticograms in primary motor cortex of primates. PLoS One 7:e47992.

70. Rubehn B, Bosman C, Oostenveld R, Fries P, Stieglitz T (2009) A MEMS-based flexible multichannel ECoG-electrode array. J Neural Eng 6:036003.

71. Henle C, Raab M, Cordeiro JG, Doostkam S, SchulzeBonhage A, Stieglitz T, Rickert J (2011) First long term in vivo study on subdurally implanted micro-ECoG electrodes, manufactured with a novel laser technology. Biomed Microdevices 13:59-68.

72. Toda H, Suzuki T, Sawahata H, Majima K, Kamitani Y, Hasegawa I (2011) Simultaneous recording of ECoG and intracortical neuronal activity using a flexible multichannel electrode-mesh in visual cortex. Neuroimage 54:203-212.

73. Slutzky MW, Jordan LR, Krieg T, Chen M, Mogul DJ, Miller LE (2010) Optimal spacing of surface electrode arrays for brain-machine interface applications. J Neural Eng 7:26004.

74. Tolstosheeva E, Gordillo-González V, Hertzberg T, Kempen L, Michels I, Kreiter A, Lang W (2011) A novel flex-rigid and soft-release ECoG array. Conf Proc IEEE Eng Med Biol Soc 2011:2973-2976.

75. Tolstosheeva E, Gordillo-González V, Biefeld V, Kempen L, Mandon S, Kreiter AK, Lang W (2015) A multi-channel, flexrigid ECoG microelectrode array for visual cortical interfacing. Sensors (Basel) 15:832-854.

76. Charvet G, Foerster M, Chatalic G, Michea A, Porcherot J, Bonnet S, Filipe S, Audebert P, Robinet S, Josselin V, Reverdy J, D’Errico R, Sauter F, Mestais C, Benabid AL (2012) A wireless 64-channel ECoG recording electronic for implantable monitoring and BCI applications: WIMAGINE. Conf Proc IEEE Eng Med Biol Soc 2012:783-786.

77. Mollazadeh M, Greenwald E, Thakor NV, Schieber M, Cauwenberghs $\mathrm{G}$ (2011) Wireless micro-ECoG recording in primates during reach-to-grasp movements. IEEE Biomed Circuits Syst Conf 201 1:237-240.

78. Chang CW, Chiou JC (2013) A wireless and batteryless microsystem with implantable grid electrode/3-dimensional probe array for ECoG and extracellular neural recording in rats. Sensors (Basel) 13:4624-4639.

79. Flint RD, Wright ZA, Scheid MR, Slutzky MW (2013) Long term, stable brain machine interface performance using local field potentials and multiunit spikes. J Neural Eng 10:056005.

80. Henle C, Raab M, Cordeiro JG, Doostkam S, SchulzeBonhage A, Stieglitz T, Rickert J (2011) First long term in vivo study on subdurally implanted micro-ECoG electrodes, manufactured with a novel laser technology. Biomed Microdevices 13:59-68. 
81. Liu J, Fu TM, Cheng Z, Hong G, Zhou T, Jin L, Duvvuri M, Jiang Z, Kruskal P, Xie C, Suo Z, Fang Y, Lieber CM (2015) Syringe-injectable electronics. Nat Nanotechnol 10:629-636.

82. Tian B, Liu J, Dvir T, Jin L, Tsui JH, Qing Q, Suo Z, Langer R, Kohane DS, Lieber CM (2012) Macroporous nanowire nanoelectronic scaffolds for synthetic tissues. Nat Mater 11:986994.

83. Liu J, Xie C, Dai X, Jin L, Zhou W, Lieber CM (2013) Multifunctional three-dimensional macroporous nanoelectronic networks for smart materials. Proc Natl Acad Sci U S A 110:6694-6699.

84. Patolsky F, Zheng G, Lieber CM (2006) Fabrication of silicon nanowire devices for ultrasensitive, label-free, real-time detection of biological and chemical species. Nat Protoc 1:17111724.

85. Javey A, Nam S, Friedman RS, Yan H, Lieber CM (2007) Layer-by-layer assembly of nanowires for three-dimensional, multifunctional electronics. Nano Lett 7:773-777.

86. Fu TM, Hong G, Zhou T, Schuhmann TG, Viveros RD, Lieber CM (2016) Stable long-term chronic brain mapping at the single-neuron level. Nat Methods 13:875-882.

87. Cakulev I, Efimov IR, Waldo AL (2009) Cardioversion: past, present, and future. Circulation 120:1623-1632.

88. Roubin GS, Cannon AD, Agrawal SK, Macander PJ, Dean LS, Baxley WA, Breland J (1992) Intracoronary stenting for acute and threatened closure complicating percutaneous transluminal coronary angioplasty. Circulation 85:916-927.

89. Jiang WJ, Wang YJ, Du B, Wang SX, Wang GH, Jin M, Dai JP (2004) Stenting of symptomatic M1 stenosis of middle cerebral artery: an initial experience of 40 patients. Stroke 35:1375-1380.

90. Oxley TJ, Opie NL, John SE, Rind GS, Ronayne SM, Wheeler TL, Judy JW, McDonald AJ, Dornom A, Lovell TJ, Steward C, Garrett DJ, Moffat BA, Lui EH, Yassi N, Campbell BC, Wong YT, Fox KE, Nurse ES, Bennett IE, Bauquier SH, Liyanage KA, van der Nagel NR, Perucca P, Ahnood A, Gill KP, Yan B, Churilov L, French CR, Desmond PM, Horne MK, Kiers L, Prawer S, Davis SM, Burkitt AN, Mitchell PJ, Grayden DB, May CN, O’Brien TJ (2016) Minimally invasive endovascular stent-electrode array for high-fidelity, chronic recordings of cortical neural activity. Nat Biotechnol 34:320-327.

91. Opie NL, van der Nagel NR, John SE, Vessey K, Rind GS, Ronayne SM, Fletcher EL, May CN, OBrien TJ, Oxley TJ (2017) Micro-CT and histological evaluation of an neural interface implanted within a blood vessel. IEEE Trans Biomed Eng 64:928-934.

92. Sefcik RK, Opie NL, John SE, Kellner CP, Mocco J, Oxley TJ
(2016) The evolution of endovascular electroencephalography: historical perspective and future applications. Neurosurg Focus 40:E7.

93. Opie NL, John SE, Rind GS, Ronayne SM, Grayden DB, Burkitt AN, May CN, O’Brien TJ, Oxley TJ (2016) Chronic impedance spectroscopy of an endovascular stent-electrode array. J Neural Eng 13:046020.

94. Schwarz DA, Lebedev MA, Hanson TL, Dimitrov DF, Lehew G, Meloy J, Rajangam S, Subramanian V, Ifft PJ, Li Z, Ramakrishnan A, Tate A, Zhuang KZ, Nicolelis MA (2014) Chronic, wireless recordings of large-scale brain activity in freely moving rhesus monkeys. Nat Methods 11:670-676.

95. Rajangam S, Tseng PH, Yin A, Lehew G, Schwarz D, Lebedev MA, Nicolelis MA (2016) Wireless cortical brain-machine interface for whole-body navigation in primates. Sci Rep 6:22170.

96. Su Y, Routhu S, Moon KS, Lee SQ, Youm W, Ozturk Y (2016) A wireless 32-channel implantable bidirectional brain machine interface. Sensors (Basel) 16:E1582.

97. Seo D, Carmena JM, Rabaey JM, Maharbiz MM, Alon E (2015) Model validation of untethered, ultrasonic neural dust motes for cortical recording. J Neurosci Methods 244:114122.

98. Song YK, Borton DA, Park S, Patterson WR, Bull CW, Laiwalla F, Mislow J, Simeral JD, Donoghue JP, Nurmikko AV (2009) Active microelectronic neurosensor arrays for implantable brain communication interfaces. IEEE Trans Neural Syst Rehabil Eng 17:339-345.

99. Bashirullah R, Harris JG, Sanchez JC, Nishida T, Principe JC (2007) Florida wireless implantable recording electrodes (FWIRE) for brain machine interfaces. IEEE Int Symp Circuits Syst Proc 2007:2084-2087.

100. Azin M, Guggenmos DJ, Barbay S, Nudo RJ, Mohseni P (2011) A battery-powered activity-dependent intracortical microstimulation IC for brain-machine-brain interface. IEEE J Solid-State Circuits 46:731-745.

101. Takahara Y, Matsuki N, Ikegaya Y (2011) Nipkow confocal imaging from deep brain tissues. J Integr Neurosci 10:121129.

102. Martial FP, Hartell NA (2012) Programmable illumination and high-speed, multi-wavelength, confocal microscopy using a digital micromirror. PLoS One 7:e43942.

103. Warden MR, Cardin JA, Deisseroth K (2014) Optical neural interfaces. Annu Rev Biomed Eng 16:103-129.

104. Baubet V, Le Mouellic H, Campbell AK, Lucas-Meunier E, Fossier P, Brúlet P (2000) Chimeric green fluorescent proteinaequorin as bioluminescent $\mathrm{Ca}^{2+}$ reporters at the single-cell 
level. Proc Natl Acad Sci U S A 97:7260-7265.

105. Wachowiak M, Cohen LB (2001) Representation of odorants by receptor neuron input to the mouse olfactory bulb. Neuron 32:723-735.

106. Williams DA, Fogarty KE, Tsien RY, Fay FS (1985) Calcium gradients in single smooth muscle cells revealed by the digital imaging microscope using Fura-2. Nature 318:558-561.

107. Mank M, Reiff DF, Heim N, Friedrich MW, Borst A, Griesbeck O (2006) A FRET-based calcium biosensor with fast signal kinetics and high fluorescence change. Biophys J 90:17901796.

108. Horikawa K, Yamada Y, Matsuda T, Kobayashi K, Hashimoto M, Matsu-ura T, Miyawaki A, Michikawa T, Mikoshiba K, Nagai T (2010) Spontaneous network activity visualized by ultrasensitive $\mathrm{Ca}(2+)$ indicators, yellow Cameleon-Nano. Nat Methods 7:729-732.

109. Slovin H, Arieli A, Hildesheim R, Grinvald A (2002) Longterm voltage-sensitive dye imaging reveals cortical dynamics in behaving monkeys. J Neurophysiol 88:3421-3438.

110. Petersen CC, Grinvald A, Sakmann B (2003) Spatiotemporal dynamics of sensory responses in layer $2 / 3$ of rat barrel cortex measured in vivo by voltage-sensitive dye imaging combined with whole-cell voltage recordings and neuron reconstructions. J Neurosci 23:1298-1309.

111. Ferezou I, Bolea S, Petersen CC (2006) Visualizing the cortical representation of whisker touch: voltage-sensitive dye imaging in freely moving mice. Neuron 50:617-629.

112. Murayama M, Larkum ME (2009) In vivo dendritic calcium imaging with a fiberoptic periscope system. Nat Protoc 4:1551-1559.

113. Ghosh KK, Burns LD, Cocker ED, Nimmerjahn A, Ziv Y, Gamal AE, Schnitzer MJ (2011) Miniaturized integration of a fluorescence microscope. Nat Methods 8:871-878.

114. Nagel G, Szellas T, Huhn W, Kateriya S, Adeishvili N, Berthold P, Ollig D, Hegemann P, Bamberg E (2003) Channelrhodopsin-2, a directly light-gated cation-selective membrane channel. Proc Natl Acad Sci U S A 100:13940-13945.

115. Zhang F, Wang LP, Boyden ES, Deisseroth K (2006) Channelrhodopsin-2 and optical control of excitable cells. Nat Methods 3:785-792.

116. Wong J, Abilez OJ, Kuhl E (2012) Computational optogenetics: a novel continuum framework for the photoelectrochemistry of living systems. J Mech Phys Solids 60:1158-1178.

117. Aravanis AM, Wang LP, Zhang F, Meltzer LA, Mogri MZ, Schneider MB, Deisseroth K (2007) An optical neural interface: in vivo control of rodent motor cortex with integrated fiberoptic and optogenetic technology. J Neural Eng 4:S143-
S156.

118. Wentz CT, Bernstein JG, Monahan P, Guerra A, Rodriguez A, Boyden ES (2011) A wirelessly powered and controlled device for optical neural control of freely-behaving animals. J Neural Eng 8:046021.

119. Iwai Y, Honda S, Ozeki H, Hashimoto M, Hirase H (2011) A simple head-mountable LED device for chronic stimulation of optogenetic molecules in freely moving mice. Neurosci Res 70:124-127.

120. Dagnew R, Lin YY, Agatep J, Cheng M, Jann A, Quach V, Monroe M, Singh G, Minasyan A, Hakimian J, Kee T, Cushman J, Walwyn W (2017) CerebraLux: a low-cost, open-source, wireless probe for optogenetic stimulation. Neurophotonics 4:045001.

121. Yashiro H, Nakahara I, Funabiki K, Riquimaroux H (2017) Micro-endoscopic system for functional assessment of neural circuits in deep brain regions: simultaneous optical and electrical recordings of auditory responses in mousés inferior colliculus. Neurosci Res 119:61-69.

122. Zhao Z, Luan L, Wei X, Zhu H, Li X, Lin S, Siegel JJ, Chitwood RA, Xie C (2017) Nanoelectronic coating enabled versatile multifunctional neural probes. Nano Lett 17:4588-4595.

123. LeChasseur Y, Dufour S, Lavertu G, Bories C, Deschênes M, Vallée R, De Koninck Y (2011) A microprobe for parallel optical and electrical recordings from single neurons in vivo. Nat Methods 8:319-325.

124. Anikeeva P, Andalman AS, Witten I, Warden M, Goshen I, Grosenick L, Gunaydin LA, Frank LM, Deisseroth K (2011) Optetrode: a multichannel readout for optogenetic control in freely moving mice. Nat Neurosci 15:163-170.

125. Voigts J, Siegle JH, Pritchett DL, Moore CI (2013) The flexDrive: an ultra-light implant for optical control and highly parallel chronic recording of neuronal ensembles in freely moving mice. Front Syst Neurosci 7:8.

126. Kwon KY, Sirowatka B, Weber A, Li W (2013) Opto- $\mu E C o G$ array: a hybrid neural interface with transparent $\mu \mathrm{ECoG}$ electrode array and integrated LEDs for optogenetics. IEEE Trans Biomed Circuits Syst 7:593-600.

127. Wang J, Wagner F, Borton DA, Zhang J, Ozden I, Burwell RD, Nurmikko AV, van Wagenen R, Diester I, Deisseroth K (2012) Integrated device for combined optical neuromodulation and electrical recording for chronic in vivo applications. J Neural Eng 9:016001.

128. Boutte RW, Merlin S, Yona G, Griffiths B, Angelucci A, Kahn I, Shoham S, Blair S (2017) Utah optrode array customization using stereotactic brain atlases and 3-D CAD modeling for optogenetic neocortical interrogation in small rodents and 
nonhuman primates. Neurophotonics 4:041502.

129. Pashaie R, Anikeeva P, Lee JH, Prakash R, Yizhar O, Prigge M, Chander D, Richner TJ, Williams J (2014) Optogenetic brain interfaces. IEEE Rev Biomed Eng 7:3-30.

130. Baumgartner RA (2014) An optogenetic brain-machine interface for spatiotemporal neuromodulation. The University of Wisconsin-Milwaukee [dissertation]. Milwaukee, WI.

131. Pashaie R, Baumgartner R, Richner TJ, Brodnick SK, Azimipour M, Eliceiri KW, Williams JC (2015) Closed-loop optogenetic brain interface. IEEE Trans Biomed Eng 62:2327-2337.

132. Iseri E, Kuzum D (2017) Implantable optoelectronic probes for in vivo optogenetics. J Neural Eng 14:031001.

133. Ramezani R, Liu Y, Dehkhoda F, Soltan A, Haci D, Zhao H, Firfilionis D, Hazra A, Cunningham MO, Jackson A, Constandinou TG, Degenaar P (2018) On-probe neural interface ASIC for combined electrical recording and optogenetic stimulation. IEEE Trans Biomed Circuits Syst 12:576-588.

134. Jia Y, Khan W, Lee B, Fan B, Madi F, Weber A, Li W, Ghovanloo M (2018) Wireless opto-electro neural interface for experiments with small freely behaving animals. J Neural Eng 15:046032.

135. Mendrela AE, Kim K, English D, McKenzie S, Seymour JP, Buzsáki G, Yoon E (2018) A high-resolution opto-electrophysiology system with a miniature integrated headstage. IEEE Trans Biomed Circuits Syst 99:1-11.

136. Liu X, Lu Y, Iseri E, Shi Y, Kuzum D (2018) A compact closedloop optogenetics system based on artifact-free transparent graphene electrodes. Front Neurosci 12:132.

137. Chow BY, Boyden ES (2013) Optogenetics and translational medicine. Sci Transl Med 5:177ps5.

138. Gaub BM, Berry MH, Visel M, Holt A, Isacoff EY, Flannery JG (2018) Optogenetic retinal gene therapy with the light gated GPCR vertebrate rhodopsin. In: Retinal gene therapy (Boon CJF, Wijnholds J, eds), pp 177-189. Humana Press, New York, NY.

139. Baughman RH, Zakhidov AA, de Heer WA (2002) Carbon nanotubes--the route toward applications. Science 297:787792.

140. Coleman JN, Khan U, Blau WJ, Gun'ko YK (2006) Small but strong: a review of the mechanical properties of carbon nanotube-polymer composites. Carbon 44:1624-1652.

141. Wang K, Fishman HA, Dai H, Harris JS (2006) Neural stimulation with a carbon nanotube microelectrode array. Nano Lett 6:2043-2048.

142. Keefer EW, Botterman BR, Romero MI, Rossi AF, Gross GW (2008) Carbon nanotube coating improves neuronal recordings. Nat Nanotechnol 3:434-439.
143. Guitchounts G, Markowitz JE, Liberti WA, Gardner TJ (2013) A carbon-fiber electrode array for long-term neural recording. J Neural Eng 10:046016.

144. Vitale F, Summerson SR, Aazhang B, Kemere C, Pasquali M (2015) Neural stimulation and recording with bidirectional, soft carbon nanotube fiber microelectrodes. ACS Nano 9:4465-4474.

145. Zhu Y, Murali S, Cai W, Li X, Suk JW, Potts JR, Ruoff RS (2010) Graphene and graphene oxide: synthesis, properties, and applications. Adv Mater 22:3906-3924.

146. Chen CH, Lin CT, Hsu WL, Chang YC, Yeh SR, Li LJ, Yao DJ (2013) A flexible hydrophilic-modified graphene microprobe for neural and cardiac recording. Nanomedicine (Lond) 9:600-604.

147. Park DW, Schendel AA, Mikael S, Brodnick SK, Richner TJ, Ness JP, Hayat MR, Atry F, Frye ST, Pashaie R, Thongpang S, Ma Z, Williams JC (2014) Graphene-based carbon-layered electrode array technology for neural imaging and optogenetic applications. Nat Commun 5:5258.

148. Kuzum D, Takano H, Shim E, Reed JC, Juul H, Richardson AG, de Vries J, Bink H, Dichter MA, Lucas TH, Coulter DA, Cubukcu E, Litt B (2014) Transparent and flexible low noise graphene electrodes for simultaneous electrophysiology and neuroimaging. Nat Commun 5:5259.

149. Liu TC, Chuang MC, Chu CY, Huang WC, Lai HY, Wang CT, Chu WL, Chen SY, Chen YY (2016) Implantable graphenebased neural electrode interfaces for electrophysiology and neurochemistry in in vivo hyperacute stroke model. ACS Appl Mater Interfaces 8:187-196.

150. Apollo NV, Maturana MI, Tong W, Nayagam DAX, Shivdasani MN, Foroughi J, Wallace GG, Prawer S, Ibbotson MR, Garrett DJ (2015) Soft, flexible freestanding neural stimulation and recording electrodes fabricated from reduced graphene oxide. Adv Funct Mater 25:3551-3559.

151. Park S, Song YJ, Boo H, Chung TD (2010) Nanoporous Pt microelectrode for neural stimulation and recording: in vitro characterization. J Phys Chem C 114:8721-8726.

152. Suyatin DB, Wallman L, Thelin J, Prinz CN, Jörntell H, Samuelson L, Montelius L, Schouenborg J (2013) Nanowire-based electrode for acute in vivo neural recordings in the brain. PLoS One 8:e56673.

153. Abidian MR, Corey JM, Kipke DR, Martin DC (2010) Conducting-polymer nanotubes improve electrical properties, mechanical adhesion, neural attachment, and neurite outgrowth of neural electrodes. Small 6:421-429.

154. Piret G, Hébert C, Mazellier JP, Rousseau L, Scorsone E, Cottance M, Lissorgues G, Heuschkel MO, Picaud S, Bergonzo P, 
Yvert B (2015) 3D-nanostructured boron-doped diamond for microelectrode array neural interfacing. Biomaterials 53:173-183.

155. Kim SP, Simeral JD, Hochberg LR, Donoghue JP, Black MJ (2008) Neural control of computer cursor velocity by decoding motor cortical spiking activity in humans with tetraplegia. J Neural Eng 5:455-476.

156. Li Z, O’Doherty JE, Lebedev MA, Nicolelis MA (2011) Adaptive decoding for brain-machine interfaces through Bayesian parameter updates. Neural Comput 23:3162-3204.

157. Shoham S, Paninski LM, Fellows MR, Hatsopoulos NG, Donoghue JP, Normann RA (2005) Statistical encoding model for a primary motor cortical brain-machine interface. IEEE Trans Biomed Eng 52:1312-1322.

158. Nishimoto S, Vu AT, Naselaris T, Benjamini Y, Yu B, Gallant JL
(2011) Reconstructing visual experiences from brain activity evoked by natural movies. Curr Biol 21:1641-1646.

159. Egert D, Najafi K (2011) New class of chronic recording multichannel neural probes with post-implant self-deployed satellite recording sites. Int Solid State Sens Actuators Microsyst Conf 2011:958-961.

160. Daneshvar ED, Kipke D, Smela E (2012) Navigating conjugated polymer actuated neural probes in a brain phantom. Proc SPIE 8340:834009.

161. Denning T, Matsuoka Y, Kohno T (2009) Neurosecurity: security and privacy for neural devices. Neurosurg Focus 27:E7.

162. Bonaci T, Herron J, Matlack C, Chizeck HJ (2015) Securing the exocortex: a twenty-first century cybernetics challenge. IEEE Technol Soc Mag 34:44-51. 